\title{
Real-time Remote Monitoring System Based on the Large Deformation Cable with Constant Resistance for Landslide Disaster and Its Application
}

\author{
Zhigang Tao ${ }^{* 1,2}$, Haipeng $\mathrm{Li}^{1,2}$, Haijiang Zhang ${ }^{1,2}$ and Xiulian Zhang ${ }^{1,2}$ \\ ${ }^{1}$ State Key Laboratory for Geomechanics \& Deep Underground Engineering, Beijing 100083, China \\ ${ }^{2}$ School of Mechanics and Civil Engineering, China University of Mining \& Technology, Beijing 100083, China
}

\begin{abstract}
It is meaningful for researching on monitoring and forecasting technology of slope stability to prevent landslide disasters, especially in the water system fields. Based on the mechanical principle of interaction among sliding mass, sliding bed and monitoring cable, a new type of energy absorbing cable (called Large Deformation Cable with Constant Resistance) which can have $2000 \mathrm{~mm}$ deformation with constant pull load of $850 \mathrm{kN}$ is developed. The mechanical principle of relative movement between sliding mass and sliding bed is proposed, and the multi-factor monitoring is transformed into single landslide mechanical monitoring. The relationship between sliding force of slope and pretightening force of monitoring cable is set up. According to the physical model experiment of landslide, the sliding force at the potential slip surface will change continually before the landslide. When the sliding force is greater than the shear resistance at the potential slip surface, the landslide will take place, which means the variation of sliding force at the potential slip surface will be ahead of displacement on the ground of slope. Consequently, monitoring the variation of sliding force at the potential slip surface is better than that of the displacement. Based on above principle and experiment, the system of real-time remote monitoring and forecasting for landslide disasters based on the large deformation cable with constant resistance is developed, which can realize the real-time remote monitoring warning of sliding force. Several landslides have been successfully predicted.
\end{abstract}

Keywords: Large deformation cable with constant resistance, landslide forecasting, remote monitoring and forecasting system, sliding force.

\section{INTRODUCTION}

Monitoring of geological disaster is an increasingly important task for today's geotechnical people asked to prevent or forecast natural disaster that could affect human lives. Landslide is one of the most costly catastrophic events in terms of human lives and infrastructure damage, most often occur as ground water builds up in a slope due to rain, snowmelt or landscape irrigation. This water increases pore pressure, hydrates and expands clay minerals, and decreases material strength, which weaken the slope. In every slope, when shearing stress along weak surface exceeds shearing resistance of the slope, a landslide occurs. Therefore, the landslide monitoring has being paid to much academic attention by researchers in the world wide, and lots of monitoring technique has been advanced. Each monitoring technique has its own advantages, disadvantages and the application range [1]. This paper described a new way for landslide monitoring, namely sliding force monitoring method, which has been applied for landslide monitoring in China.

China is a country frequently suffered from various geological hazards. Landslides are common in China, particularly in the southwest and in the northwest, these

*Address correspondence to this author at the School of Mechanics and Civil Engineering, China University of Mining \& Technology, beijing, 100083, P.R. China; Tel: +8615810687582; E-mail: taozhigang1981@163.com regions surrounded by many steep mountains, characterized by climatic conditions and a geological setting favorable to the occurrence of landslides. With the boom of economy and a great deal of ongoing engineering projects such as transportation and resource development, as well as the influence of environmental changes, damages caused by landslide are sharply increasing. In China, around 700 local governments have suffered from geologic hazards for long and tones millions of residents living in these areas face threatens of serious geologic hazards. Therefore, it is particularly important to develop cost-effective reliable landslide monitoring systems and technologies [1-5].

Early warning monitoring for landslides becomes more and more important. Especially, the monitoring for landslides in man-made structures, such as bridges, dams, water system structure and hydraulic engineering, plays a key role in the prevention and mitigation of risks related to natural and technological hazards. In most cases, the occurrence of landslides is originated by the loss in equilibrium of the soil and rock mass due to changes in one or more parameters, such as seismic noise, ground displacements, piezometric level and rainfall, which contribute to leaving the mass itself unstable. Through continuous monitoring the correlative parameters, the dynamics activity of the landslide can be observed. In the past twenty years, many monitoring methods were proposed, but the dominant method is displacement amount testing, such as mechanics-electronics displacement measuring, topographic surveys, GPS surveys, total station, borehole 
tilt-meter, distomat, pendulums and extensometers, etc. These conventional monitoring techniques give information about displacements only in a few numbers of points. In addition, it is expensive and time consuming for a large number of points to measure on a continuous basis. In fact, the landslide will occur when the sliding forces are exceeds the resisting forces on the sliding plane. So, if the sliding force distribution and changes of the landslide bodies can be monitored, the occurrence of landslides will be predicted accurately [2-11].

It is difficult to determine where and when the landslide will be occurred. We have to find a necessary and sufficient condition triggering landslide as a monitoring parameter, but this work is a rather difficult task. This paper introduces a totally new solution in this field of application, providing many advantages over conventional instruments. We present the sliding force monitoring approach to predict the occurrence of landslides, using intelligent sensingacquisition-transmission system equipments based on the Large Deformation Cable with Constant Resistance (abbreviated CR-LD cable) which installed in landslide mass to monitor the sliding force variations along the sliding surface in landslide bodies. Sliding force monitoring approach has the potential to provide automatic continuous force monitoring with high accuracy for large slopes, extensive landslide areas, open pit mines, etc.
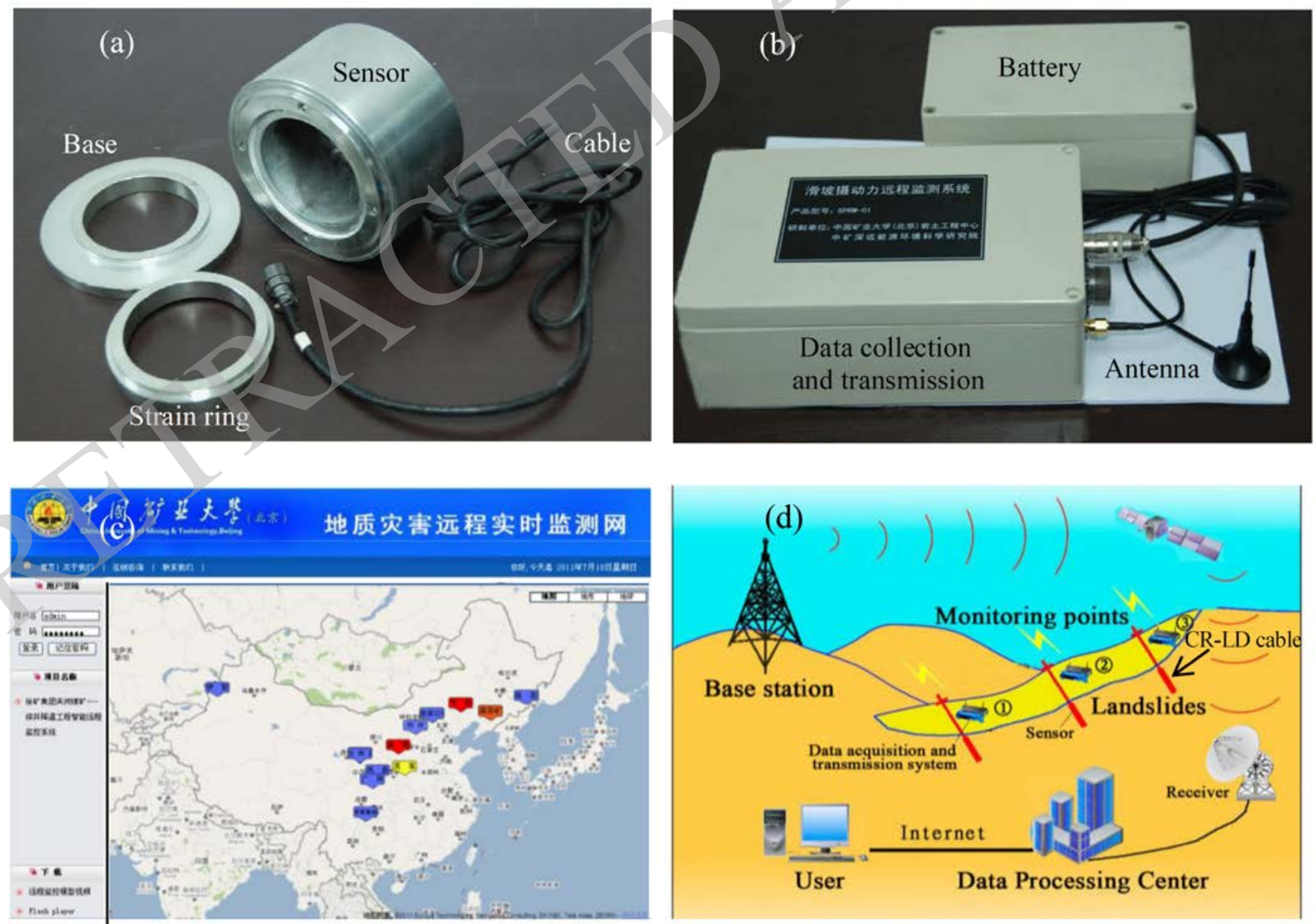

\section{HIGH-RESOLUTION SLIDING FORCE MONITORING SYSTEM}

According to sliding force monitoring principle, a new type of high resolution sliding force monitoring system called "remote monitoring warning system of sliding force" (abbreviated SPRM) has been developed. This system is composed of CR-LD cable, sensor system, intelligent acquisition system, Beidou satellite transmission system, and intelligent receiving terminal system (Fig. 1).

\subsection{CR-LD Cable}

The CR-LD cable consists of nut, face plate, steel tendon and energy absorber unit. Steel tendon is made of six or more smooth and high strength steel strands with $\varphi 15.24 \mathrm{~mm}$ diameter. The yielding action of the CR-LD cable is provided through the energy absorber unit, this unit is a $133 \mathrm{~mm}$ external diameter, $2000 \mathrm{~mm}$ long hollow cylinder, truncated on both the end. Energy absorber unit consists of the casing tube, the frictional cone unit and the stop element. When the CR-LD cable is subjected to a static or dynamic load, and load exceed over the constant resistance force (we also called it resistance of friction between the cone unit and the casing tube), the frictional cone unit will move in the casing tube along the axis. The cone unit moves over alone the tube and

Fig. (1). (a) High-resolution sensor system, (b) intelligent data acquisition system, (c) web-based force monitoring system, and (d) working principle of whole monitoring system. 
friction fixed at $2000 \mathrm{~mm}$ from the cable's end as seen in Fig. (2). The tube is fixed by the cement plaster in the bottom of borehole.

Having a larger diameter than the constant resistance tube, the cone unit's strength must be over the tube avoid creep. The frictional movement of the cone unit alone the tube is stopped by the stop element and the baffle at the two sides of energy absorbing unit. Because of environmental complexity in the borehole, a kind of special filling material is introduced against corrosion of energy absorbing units. The diameter of cone unit can be adjusted to improve the frictional force between the tube and the cone unit until a designed yield load is reached (e.g. $850 \mathrm{kN}$ ). When the pull load attains the yield load, the tube starts deforming due to the materials strength of tube is inferior to the cone unit ones. The cone unit sliding through the tube is controlled by the frictional resistance.

\subsection{Sensor System}

The sensor system which is installed outside end of the CR-LD cable has measuring and sensing function. In order to acquire precise monitoring data and increase service life, CR-LD cable must be designed to satisfy following characteristic as, high strength, low relaxation and high anticorrosion. Before the CR-LD cable is designed, it is important to collect the detail geological investigation data (including the geological cross section and the physical and mechanical properties) where nearby the monitored areas in order to ensure that the anchor cable can be installed through the sliding surface.

\subsection{Intelligent Acquisition Transmission System}

The signal acquisition and transmission equipment is the main component of the system. This equipment is composed of data acquisition module, store module, transmission module (TC 35i module), power management module, subscriber identity module slot, battery and radio aerial (Fig. 1 (b)). Solar cells can be used to provide continuous power supply for equipment in the region of sufficient solar illumination. Small antennas are set on the measurement points, and then they are connected though the base station to the wireless receiver, respectively. The receiver transfers the data transmitted from the satellites through a cable to a personal computer at the control office [10].

\subsection{Intelligent Receiving Terminal System}

Intelligent receiving terminal system is composed of signal receiver, signal processor and a special analysis software witch is installed in the computer. The monitoring results and their interpretation, used along with the weather forecast and other information to assess slope stability, are provided to the client through the Internet. The client opens the Home Page (Fig. (1c)), and inputs the login name and the password into the login page. The first page shows the measurement points and the status of the stability. The computer controls the whole system and analyzes the data in order to obtain sliding force at all the measurement points. The measurement results are shown on the monitor screen in real time, and working principle of monitoring system is shown in Fig. (1d).

\section{APPLICATION TEST}

\subsection{General Introduction to the Project}

The remote force monitoring system has been performed in Nanfen open pit iron mine in China, which is located at 123.83 degrees east longitude and 41.12 degrees north latitude. The iron mine was put into operation since 1957, and the area of the pit is approximately, $3 \mathrm{~km}$ in length by $1 \mathrm{~km}$ in wide. The final height of the slope at present is about $756 \mathrm{~m}$. The height of each bench is $24 \mathrm{~m}$ and the average angle of the slope in western side is 46 degrees.

Nanfen open pit iron mine is located in the south wing of Heibei montain inversed anticline, the stratum is mainly composed of the Archean Anshan group, Algonkian Liaohe group, Sinian system and Quaternary system. The trend of tectonic line is NNE. Slope of the stope is cut by 5-6 joints, and two of them have impact on the stability of the heading side: (1) Major joint: average attitude is $295^{\circ} / 48^{\circ}$, and it has the trace of sliding, the value of roughness of the joints is about 2-4. The joints in the slope are through, and they form the main sliding surface of the landslide of heading side. (2) Secondary joint: average attitude is $291^{\circ} / 13^{\circ}$, spreading extensively, and small dip angle. The surface where the joints exposing has the trace of water flow, since this set of joints dip into stope, and exposing on the surface of slope, they may well become the bottom sliding face of slip mass.
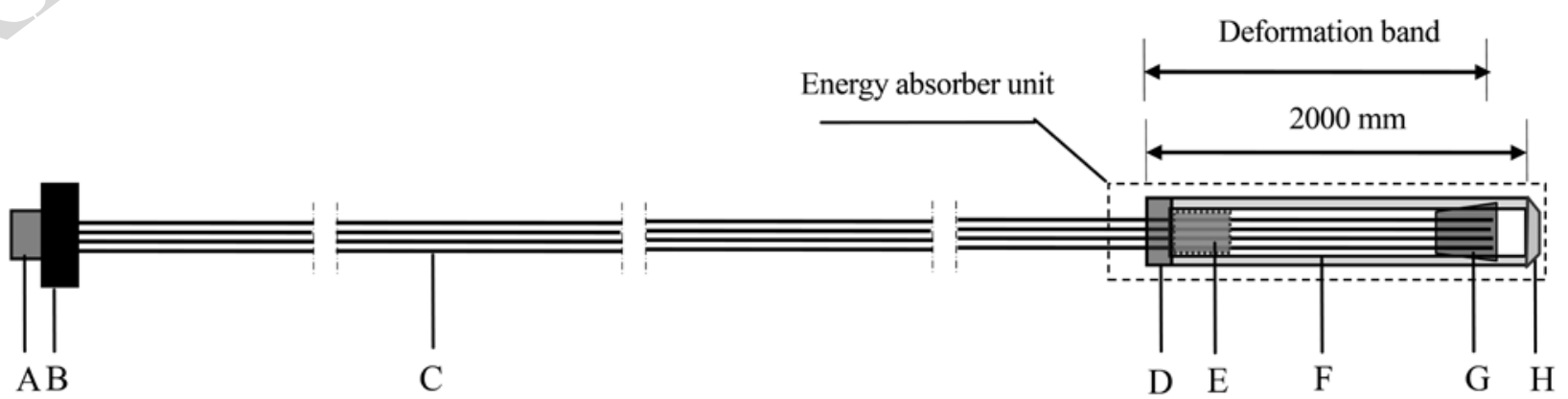

A-nut; B-face plate; C-steel tendon, composed of 6 steel strands with $\varphi 15.24$ diameter; D-baffle; E-fill material; F-casing tubes; G-frictional cone unit; H-stop element ( $\varphi 133 \mathrm{~mm})$

Fig. (2). Components of a CRLD cable. 


\subsection{Distribution of Monitoring Points}

The bird's-eye view of the Nanfen open pit iron mine and the measurement points on the slope are illustrated in Fig. (3)

As illustrated in Fig. (3) painted cycles in the figure represent the sliding force monitoring points. Monitoring equipments including sliding force monitoring and the displacement monitoring equipments have been installed on July 4th 2010. The sliding force remote monitoring system has been placed, at 20 monitoring points as illustrated in Fig. (3b) by painted black cycles. The green tri-angel represents the displacement monitoring points of J31 in 430 bench.

\subsection{Monitoring curve}

Fig. (4a) shows the cross section along the point measurement of J31 and NO.1-2. NO.1-2 is installed on 394 bench in Nanfen open pit iron mine and the surface displacement monitoring point J31 is in 430 bench. Fig. (4b) shows a portion of the continuous monitoring results at measurement point of NO.1-2 and J31 from 4th July 2010 to 14th December 2010.

The curves include four parameters: sliding force ( $\mathrm{i}$ ), surface displacement ( ii ), accumulative amount of mining ( iii ) and rainfall curve (iv ).

\section{SLIDING FORCE AND DISPLACEMENT RESULTS AND ANALYSIS}

According to the monitoring curves including sliding force curve, displacement curve, accumulative mining curve and rainfall curve illustrated in Fig. (4b), we can see that the sliding force curve on NO.1-2 point is more sensitive than the ones of displacement on J31 point which is installed near the NO.1-2. As illustrated in Fig. (4b), the sliding force variation and the displacement changes are small before the start point of A, on the 26th July 2010, and it indicates that the slope is stable. Then, when the sliding force monitoring curve arrived at point $\mathrm{A}$, with the increase in time, the sliding force variance ratio begin to increase, however, there is no any crack on the ground. In order to protect the safety of sliding mining, decision maker of open pit mine gave the order to stop mining (a)
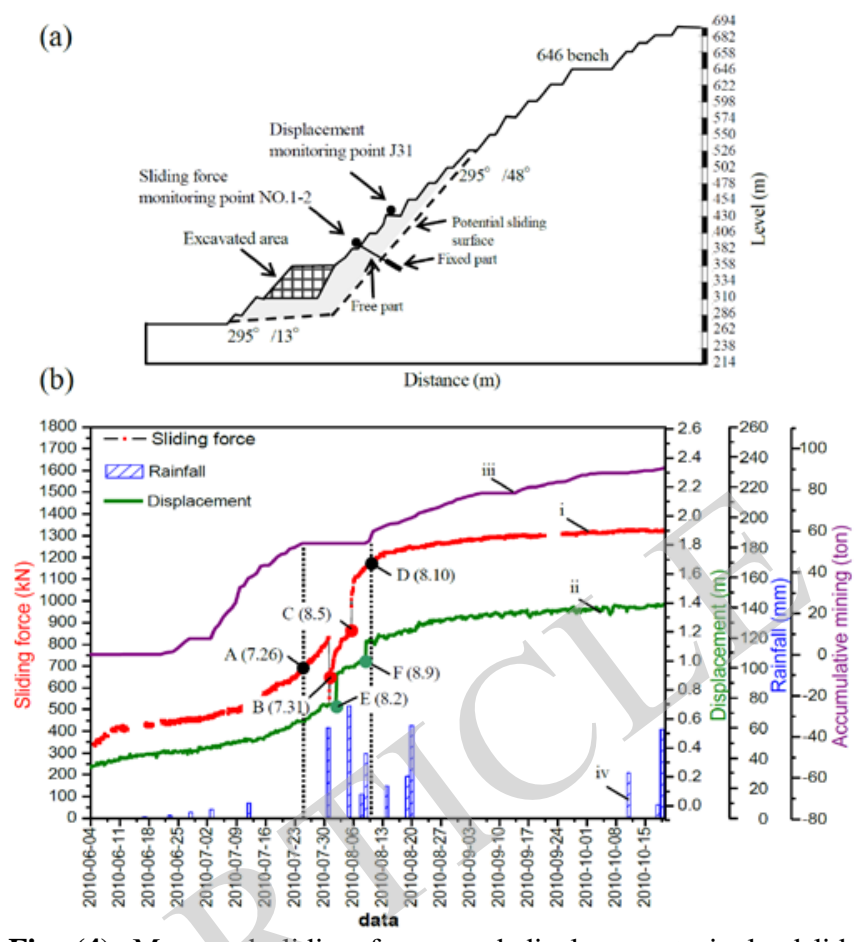

Fig. (4). Measured sliding forces and displacements in landslide area: (a) cross section along with measured points J31 and NO.1-2, (b) sliding force, displacement measured, accumulative mining and rainfall with respect to time.

based on the monitoring curve of sliding force, and timely evacuation of personnel and equipment. This information can be demonstrated by the accumulative mining curve shown in Fig. (4b). From the Fig. (4b), we can see that mining quantity is zero between the A point and the $\mathrm{D}$ point.

At point B, on the 31 July 2010, there is a sudden drop in the sliding force monitoring curve (called mutation), and the warning signal is issued. On the spot, around 1 meter sliding trace began to appear on the 526 bench (Fig. 5a). With the sliding, large of rolling stones impact to the 358 bench along the slope. Because of evacuation of personnel and equipment in time working on the 358 bench on 26 July 2010 , there is no any casualty. However, the surface displacement monitoring point without any reaction at this time. Until on the 2nd

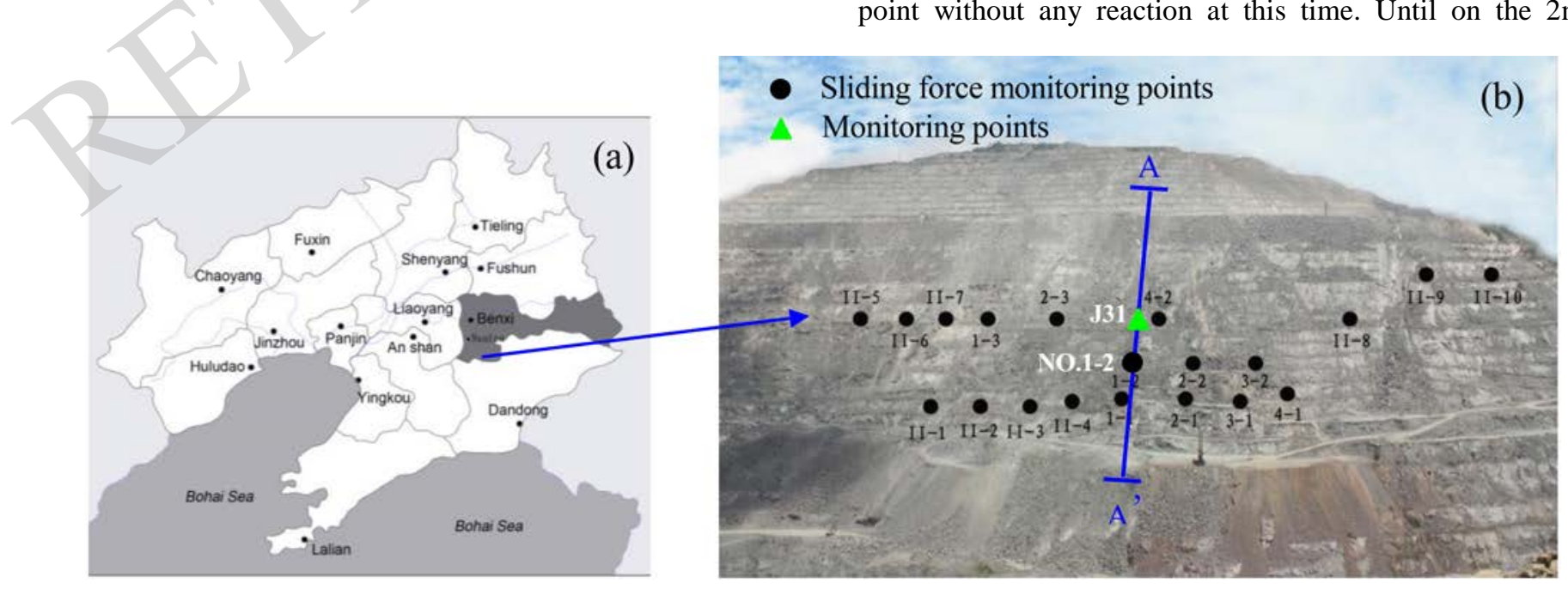

Fig.(3). (a) Outline of Nanfen open pit iron mine: (b) sliding force monitoring points on the slope. 


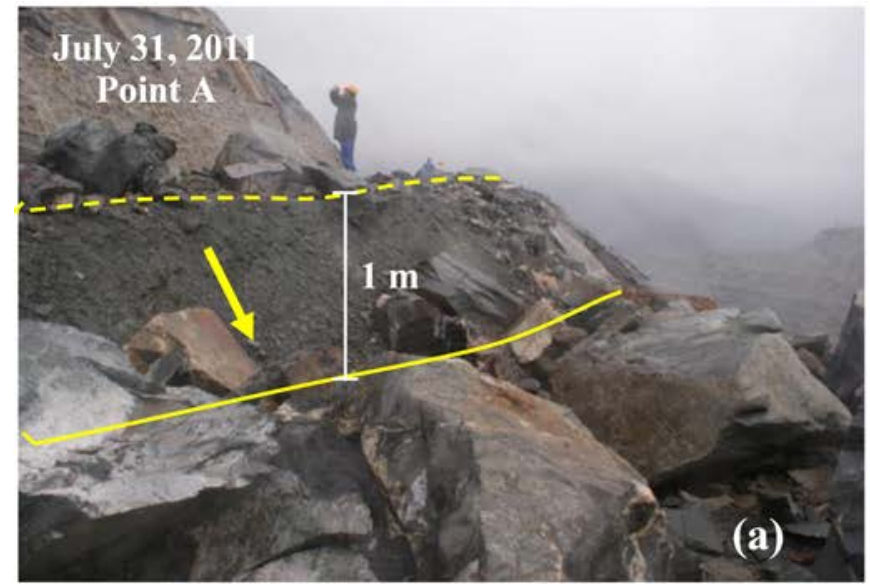

(A point)sliding on 526 bench, divide $1 \mathrm{~m}$

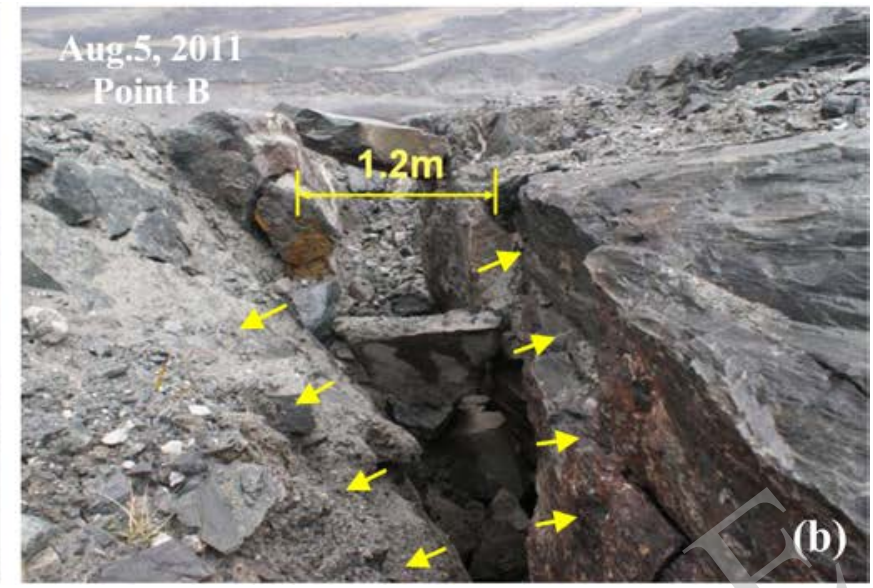

(B point)crack on 430 bench width of $1.2 \mathrm{~m}$, length of $48 \mathrm{~m}$.

Fig. (5). Sliding and crack : (a) sliding body moved, (b) crack propagated on the top of the slope on 430 bench.

August 2010, two days later issued a warning by the sliding force monitoring curve, J31 monitoring of surface displacement curve to demonstrate mutations ( $\mathrm{E}$ point ).

At point C, on the 5th August 2010, there is a sudden drop in the sliding force monitoring curve again (called mutation), and the warning signal is issued again. On the spot, crack began appearing on 430 bench which is above the monitoring point, and the crack was $2 \mathrm{~m}$ deep, $1.2 \mathrm{~m}$ wide and $48 \mathrm{~m}$ long, running through 4 benches (Fig. 5b). However, the surface displacement monitoring point without any reaction until 9th August, the curve of J31 surface displacement monitoring point show the going up(F point) four days after the early warning send out by sliding force curve.

At point D, on the 10 August 2010, sliding monitoring curve and the displacement monitoring curve become stable, warning signal removed, mining on 358 bench which is below the landslide restart.

These two mutations for sliding force monitoring curve is not that the mining, but that the heavy rainfall which is 50 years of the worst storm in Nanfen open pit iron mine. Fig. (4b) shows that on 31 July 2010, the maximum rainfall is around $70 \mathrm{~mm}$ and on 5th August 2010, the maximum rainfall is around $82 \mathrm{~mm}$.

It is found that the sliding force monitoring system can predict the collapse time before the slope failure and collapse occurred. It can be pointed out that the sliding force monitoring network provides engineers and geologists with early notification of landslide activity.

From these monitoring results, it can provide that the sliding remote force monitoring system is highly accurate and precise measurement. Practical applications for a large open pit, a landslide area, a road side slope, tunnel entrances, slope monitoring along the gas pipeline, stability monitoring of slope due to seismic, stability monitoring of active fault etc., have been demonstrated of the successful application of this system in rock engineering. Currently, ten landslides in China are monitored in real-time using 166 sliding remote force monitoring systems.

\section{CONCLUSION}

The sliding force monitoring has been proposed as a new approach for rapid stability assessment available in the open pit iron mine. The stability of the present iron mine has successfully been confirmed through the detection of the changes of sliding force in rock mass bodies by the high-resolution sensor system and CR-LD cable. Through monitoring, we have successfully forecasted the occurrence of landslides and cracks.

The theory of the sliding force has been developed in this article, so as to predict the landslide occurrence by analyzing the sliding force changes in landslide bodies. From these analyses, it has been clarified that the sliding force monitoring curve includes sufficient information to identify the large deformation induced in rock mass bodies after the warning system.

According to the experimental result from the field trial in Nanfen open pit iron mine, this monitoring system is very effect. Since the proposed method has many advantages in terms of high resolution, high-sensitivity, easy networking to monitor landslides in a large area, it can also be used to monitor the engineering disasters in large open pit, a landslide area, a road side slope, tunnel entrances, slope monitoring along the gas pipeline, stability monitoring of slope due to seismic and stability monitoring of active fault.

\section{CONFLICT OF INTEREST}

The author confirms that this article content has no conflict of interest.

\section{ACKNOWLEDGEMENTS}

Declared none.

\section{REFERENCES}

[1] S. K. Mittal, M. Singh, P. Kapur, B K. Sharma, and M A. Shamshi, "Design and development of instrumentation network for landslide monitoring and issue an early warning," Journal of Scientific \& Industrial Research, vol. 67, pp. 361-365, 2008. 
[2] Z. Pinggen, Z. Baishen, G. Jingjun, Li. Donghang, D. Zhigang, and F. Yanming, "A demonstrative GPS-aided automatic landslide monitoring system in Sichuan Province," Journal of Global Positioning Systems, vol. 4, no. 1-2, pp.184-191, 2005.

[3] D. Zhi-Yong, L. Yong, Z. Li-Xun, O. Zhong-Hua, Z. Ce, and L. Yong-Zhi, "Landslide monitoring based on high- resolution distributed fiber optic stress sensor,” Journal of Electronic Science and Technology of China, vol. 6, no. 4, pp. 416-419, 2008.

[4] M.C. He, J.L. Feng, and X.M. Sun, "Stability evaluation and optimal excavated design of rock slope at Antaibao open pit coal mine, China," International Journal of Rock Mechanics \& Mining Sciences, vol. 45, pp. 289-302, 2008.

[5] M. C. He, Engineered Slopes in China-Approaches and Case Studies, China, China Coal Industry Publishing House, 2008, pp. 1-12.

[6] N. Shimizu, and T. Funatsu, "Displacement monitoring system using GPS for excavated and natural slopes," In: The EITJAPAN-AIT Joint Workshop on "Geo-Risk Engineering \& Management”, 2005, pp. 47-56.
[7] M.G. Angeli, A. Pasuto, and S. Silvano, "A critical Review of Landslide Monitoring Experiences,” Engineering Geology, vol. 55, pp. 133-147, 2000.

[8] M.C. He, Z. Chen, H. Zhang, and Y. Jiang, "Analysis of large deformation and the numerical simulation of the slope sliding process," In: Proceeding of the, $99^{\text {th }}$ International Symposium on Mining Science and Technology, Beijing, China, 1999, pp. 435-438.

[9] M. C. He, X. Wu, X. M. Sun, and Z. Y. Heng, "Reliving forecasting theory to the key position of a huge ancient landslide body," In: $2^{\text {nd }}$ Asian Rock Mechanics Symposium, Beijing, 2001, pp. 409-412.

[10] M. C. He, "Disaster mechanism of deep-seated coal mine and the advances in monitoring research," Coal Science and Technology Magazine, vol. 1, pp.1-5, 2007. (in Chinese).

[11] S. Wang, M. C. He, and Y. Jia. "Anchoring mechanism of pre-stressed anchor cables under concentrated tension and dispersive pressure," Journal of University of Science and Technology, Beijing, vol. 27. no. 3, pp. 279-282, 2005. (in Chinese)

Received: April 18, 2015

Revised: May 30, 2015

Accepted: June 05, 2015

(c) Tao et al.; Licensee Bentham Open.

This is an open access article licensed under the terms of the Creative Commons Attribution Non-Commercial License (http://creativecommons.org/licenses/ by-nc/3.0/) which permits unrestricted, non-commercial use, distribution and reproduction in any medium, provided the work is properly cited. 